\title{
Physical and rheological properties of Titanium Dioxide modified asphalt
}

\author{
Rosnawati Buhari ${ }^{1, *}$, Mohd Ezree Abdullah ${ }^{1}$, Mohd Khairul Ahmad ${ }^{2}$, Ai Ling Chong ${ }^{1}$, Rosli \\ Haini $^{3}$, and Siti Khatijah Abu Bakar ${ }^{1}$ \\ ${ }^{1}$ Faculty of Civil and Environmental Engineering, Universiti Tun Hussein Onn Malaysia, 83000 \\ Batu Pahat, Johor Malaysia \\ ${ }^{2}$ MINT-SRC, UniversitiTun Hussein Onn Malaysia, 86400, Parit Raja, BatuPahat Johor, Malaysia \\ ${ }^{3}$ Faculty of Civil Engineering, Universiti Teknologi Malayia, Skudai, Johor, Malaysia
}

\begin{abstract}
Titanium Dioxide $\left(\mathrm{TiO}_{2}\right)$ has been known as a useful photocatalytic material that is attributed to the several characteristics includes high photocatalytic activity compared with other metal oxide photocatalysts, compatible with traditional construction materials without changing any original performance. This study investigates the physical and rheological properties of modified asphalt with $\mathrm{TiO}_{2}$. Five samples of asphalt with different concentration of $\mathrm{TiO}_{2}$ were studied, namely asphalt $2 \%, 4 \%, 6 \% 8 \%$ and $10 \% \mathrm{TiO}_{2}$. The tests includes are penetration, softening point, ductility, rotational viscosity and dynamic shear rheometer (DSR) test. From the results of this study, it is noted that addition of $\mathrm{TiO}_{2}$ has significant effect on the physical properties of asphalt. The viscosity tests revealed that asphalt $10 \% \mathrm{TiO}_{2}$ has good workability among with reducing approximately $15^{\circ} \mathrm{C}$ compared to base asphalt. Based on the results from DSR measurements, asphalt $10 \% \mathrm{TiO}_{2}$ has reduced temperature susceptibility and increase stiffness and elastic behaviour in comparison to base asphalt. As a result, $\mathrm{TiO}_{2}$ can be considered to be an additive to modify the properties of asphalt.
\end{abstract}

\section{Introduction}

Asphalt is the binder in the asphaltic concrete mixture for the construction of road surface. Asphalt is a liquid at higher temperature and is inelastic at lower temperature. These behaviors can result at higher temperature and cracking at low temperature. Therefore, modifying asphalt is now a common alternative to enhance the performance of asphalt by addition of various modifiers based on the aims and objectives of the purposes to be using for. In recent years, nanomaterials are commonly used as additives for hot mix asphalt or warm mix asphalt [1-2]. Several nanomaterials used includes nanoclay, nano hydrated lime, titanium dioxide nanoparticle, carbon nanoparticles etc. In general, Nanotechnology will produce benefits in two ways by making existing products and processes more cost effective, durable and efficient and by creating entirely new products. It also improve the storage stability in polymer modified asphalt, increase the resistance to UV aging, reduce

\footnotetext{
* Corresponding author: rosna@uthm.edu.my
} 
the moisture susceptibility under water, snow and deicers, improve the properties of asphalt mixtures at low temperature, improve the durability of asphalt pavements, save energy and cost, decreasemaintenance requirements [3]. Titanium Dioxide is naturally occurred oxide that easy to find material in the earth's crust that is $0.6 \%$. Its chemical formula is $\mathrm{TiO}_{2}$ and it belongs to the family of transition metal oxides. The bulk material of $\mathrm{TiO}_{2}$ is well known to have three crystal structures: anatase, rutile and brookite [4]. The fundamental structure unit in three $\mathrm{TiO}_{2}$ crystals is $\left(\mathrm{TiO}_{6}\right)$ octahedra, but their modes of arrangement and links are different. Brookite and anatase are metastable and transform exothermally and irreversibly to rutile over a range of temperatures [5-6]. The composition of $\mathrm{TiO}_{2}$ is temperature dependant. $\mathrm{TiO}_{2}$ normally used has nanoparticles with a great specific surface (area to volume ratio) and diameter inferior to $100 \mathrm{~nm}$. FESEM and Transmission Electron Microscopy (TEM) is the apparatus that is frequently used to determine the characteristic of $\mathrm{TiO}_{2}$ through its morphology and to observe the characteristic of the $\mathrm{TiO}_{2}$ growth, composition etc. The TEM study is to confirm the FESEM study regarding the diameter of the sample.

\section{Experiment}

\subsection{Material and sample preparation}

The base asphalt was of $80 / 100$ penetration grade. Titanium dioxide white powder, procured from industry was used as a modifier for asphalt. The physical properties of the base asphalt and modifier $\mathrm{TiO}_{2}$ are listed in Table 1 and the morphology of both $\mathrm{TiO}_{2}$ powder as shown in Fig.1. The particle size ranges from 40 to $70 \mathrm{~nm}$ was observed and the Energy Dispersive X-ray Spectroscop (EDS) tests conform that the powder is Titanium dioxide has crystal structures of Anatase.

Table 1. Physical properties of asphalt and $\mathrm{TiO}_{2}$ modifier.

\begin{tabular}{|l|l|l|l|l|}
\hline Material & Properties & Unit & Limits & Value \\
\hline Asphalt 80/100 & Specific gravity & - & $1.00-1.05$ & 1.03 \\
& Penetration @ 25 2 $\mathrm{C}$, & $0.1 \mathrm{~mm}$ & $80-100$ & 70 \\
& Softening point & ${ }^{\circ} \mathrm{C}$ & $42-52$ & 47 \\
& Viscosity @ 35 $35^{\circ} \mathrm{C}$ & $($ Pa.s) & $\geq 3$ & 0.5 \\
$\mathrm{TiO} 2$ & Ductility @ $25^{\circ} \mathrm{C}$ & $\mathrm{cm}$ & $\geq 100$ & $>100$ \\
& Size & $\mathrm{nm}$ & - & $40-60$ \\
\hline
\end{tabular}

\subsection{Experimental Procedure}

In the process of modifying asphalt, type of the modifying agent, preparation temperature and modification process will influence the performance of modified asphalt. Considering the different kinds of base asphalt, polymers and nanomaterial the preparation process of modified asphalt can vary dramatically. In addition to these factors, control of the preparation process parameters such as shearing speed, temperature and time to prepare the modified asphalt with good compatibility and thermal storage stability are also areas of work for future research in nanomaterial modified asphalt. To reduce the viscosity in preparing the modified asphalt it is necessary to raise the temperature to facilitate nanoparticle diffusion (Brownian motion). Since asphalt is easily aged with oxygen during the composite preparation, the temperature of the mixture should not be too high and the shearing time should not be too long which presents a paradox [7]. In this study, the $\mathrm{TiO}_{2}$ modifier was used for the preparation of five differently modified asphalt samples at 
concentration of $2 \%, 4 \%, 6 \%, 8 \%$ and $10 \%$. The asphalt was melted and a Silverson high shear mixer was used for the mixing at a constant temperature of $155^{\circ} \mathrm{C}$ and speed of 3500 rpm for $45 \mathrm{~min}$ to produce homogeneous mixtures. The homogeneity of mixtures evaluated using storage stability test for every single mixture.

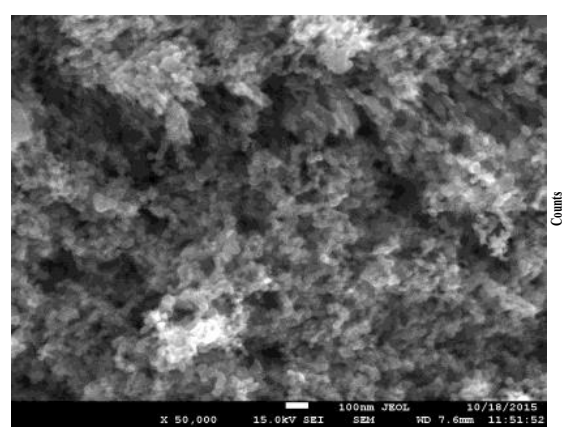

(a)

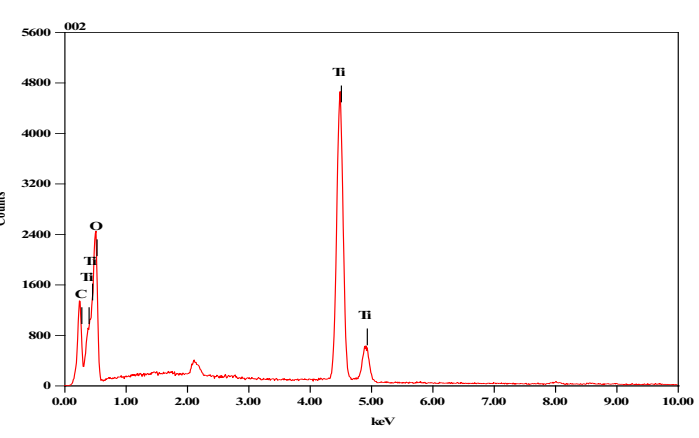

(b)

Fig. 1. (a) Fe-SEM image of $\mathrm{TiO}_{2}$ and (b) EDS image.

For physical properties penetration test (ASTM D5), softening point (ASTM D36) and ductility (ASTM D113) were run to ensure reproducibility and to evaluate the properties changes of modified asphalt in comparison to the original asphalt. The penetration, softening point and ductility are the test to measure stiffness, temperature at the asphalt starts to become a fluid and the maximum distance of asphalt to elongate at specific rate and temperature respectively. Others, the viscosity of the asphalt were measured by rotational viscometer as per ASTM D4402. The original and modified asphalt were tested at various temperature that are $120^{\circ} \mathrm{C}, 135^{\circ} \mathrm{C}, 150^{\circ} \mathrm{C}, 165^{\circ} \mathrm{C}$, and $180^{\circ} \mathrm{C}$. The dynamic shear rheometer (DSR) is used to characterise the viscous and elastic behaviour of asphalt at high and intermediate temperature. Other than that, DSR measures the complex modulus $\mathrm{G}^{*}$ and phase angle, $\delta$ at the desired temperature and frequency of loading as per AASHTO T315. The failure temperature are considered for all asphalt blends according to Superpave specification for $\mathrm{G}^{*} / \mathrm{sin} \delta$ values less than $1.0 \mathrm{kPa}$ in case of unaged asphalt and less than $2.2 \mathrm{kPa}$ after rotational thin film oven test (RTFOT).

\section{Results and discussions}

\subsection{Physical Properties}

The influence of various concentration of $\mathrm{TiO}_{2}$ on the properties of asphalt in the value of penetration, softening point and ductility are given in Table $2 . \mathrm{All}_{\mathrm{TiO}}$ modified asphalts shows pronounced decrease in penetration with the strongest difference is asphalt $10 \%$ $\mathrm{TiO}_{2}$ for up to approximately $36 \%$ from the original asphalt. Conversely, the softening point values were slightly decreasing for $0.4 \%$ for asphalt $2 \% \mathrm{TiO}_{2}$ and increasing for up $7.8 \%$ for other percentage of $\mathrm{TiO}_{2}$ blend. The decrease in penetration and increase in softening point denote an increasing in stiffness of $\mathrm{TiO}_{2}$. The Penetration Index (PI) value in the table also assured the stiffness of the blend, where increasing PI value denoted the rising the hardness and also leads to improved temperature susceptibility of $\mathrm{TiO}_{2}$ blend and vice versa. It is noted that asphalt $10 \% \mathrm{TiO}_{2}$ is the most hardness among asphalts blend and strongly comparable with the original asphalt. Meanwhile the viscosity of the asphalt $8 \%$ and $10 \% \mathrm{TiO}_{2}$ are decreasing leads to improve its workability. It also noted that ductility 
value for all $\mathrm{TiO}_{2}$ blends are all more than $100 \mathrm{~mm}$, which passed the standard requirements.

Table 2. Physical properties of asphalt and $\mathrm{TiO}_{2}$ blends.

\begin{tabular}{|l|c|c|c|c|c|}
\hline $\begin{array}{l}\text { Control \& } \mathrm{TiO}_{2} \\
\text { Modify asphalt }\end{array}$ & $\begin{array}{c}\text { Penetration } \\
@ 25 \mathrm{C}\end{array}$ & $\begin{array}{c}\text { Softening } \\
\text { Point }\end{array}$ & PI & $\begin{array}{c}\text { Viscosity@135 }{ }^{\circ} \mathrm{C}, \\
\text { Pa.s }\end{array}$ & Ductility \\
\hline $\mathrm{Control} 80 / 100$ & 89.1 & 46.4 & -0.71 & 0.5 & $>100$ \\
$\mathrm{TiO}_{2} 2 \%$ & 88.2 & 46.2 & -0.80 & 0.6 & $>100$ \\
$\mathrm{TiO}_{2} 4 \%$ & 75.3 & 46.6 & -1.07 & 0.6 & $>100$ \\
$\mathrm{TiO}_{2} 6 \%$ & 67.1 & 50.0 & -0.5 & 0.6 & $>100$ \\
$\mathrm{TiO}_{2} 8 \%$ & 60.8 & 48.6 & -1.1 & 0.5 & $>100$ \\
$\mathrm{TiO}_{2} 10 \%$ & 56.4 & 49.2 & -2.85 & 0.5 & $>100$ \\
\hline
\end{tabular}

\subsection{Viscosity}

The viscosity value at $135^{\circ} \mathrm{C}$ shows increasing for up to $4 \% \mathrm{TiO}_{2}$ and same as asphalt control for asphalt $6 \%$, asphalt $8 \% \mathrm{TiO}_{2}$ and $10 \% \mathrm{TiO}_{2}$. It is proved that asphalt $\mathrm{TiO}_{2}$ passed the pumped and handled ability as it lower than 3Pa.s. Moreover, the mixing and compaction temperature of the mixture also obtained from the viscosity value for several temperatures where determined based on the reference viscosity values of 0.17-0.2 Pa.s and $0.28-0.3$ Pa.s. It can be observed from Fig. 2 that the viscosity values decrease immediately with increasing test temperature for all concentration of $\mathrm{TiO}_{2}$. It is also shows that the concentration of $10 \% \mathrm{TiO}_{2}$ blends has the lowest viscosity value results lowest mixing and compaction temperature. The mixing and compaction temperature were reduced significantly to approximately about $5^{\circ} \mathrm{C}$ and $15^{\circ} \mathrm{C}$ respectively.

\subsection{Rheological properties of $\mathrm{TiO}_{2}$ blends}

\subsubsection{Isochronal plots}

Isochronal plots in Fig. 3 and Fig.4 plot a viscoelastic variable, complex modulus and phase angle, $\delta$ versus temperature $\left({ }^{\circ} \mathrm{C}\right)$ at constant frequency of $1 \mathrm{rad}$ (approximately $0.1592 \mathrm{~Hz}$ ) and $10 \mathrm{rad}$ (approximately $1.592 \mathrm{~Hz}$ ). The isochronal plot is correspondence to the expected response of the asphalt binder under actual traffic conditions. It is noted that, at $1 \mathrm{rad}, \mathrm{G}^{*}$ values asphalt $10 \% \mathrm{TiO}_{2}$ is higher that original asphalt thus leading to improved temperature susceptibility among all investigated asphalt blending. Moreover, the same pattern obtained at $10 \mathrm{rad}$ where complex modulus of asphalt $10 \% \mathrm{TiO}_{2}$ is higher and the phase angle is lower than original asphalt. Other than that, all asphalt blending show pronounce increasing in $\mathrm{G}^{*}$ values at low frequency and temperature, as well as at high frequency and temperature which represents an improvement in terms of the temperature susceptibility [8-9]. Moreover, it is noted that the asphalt $10 \%$ has a slightly lower phase angle than the other which means it has better elastic recovery performance. 


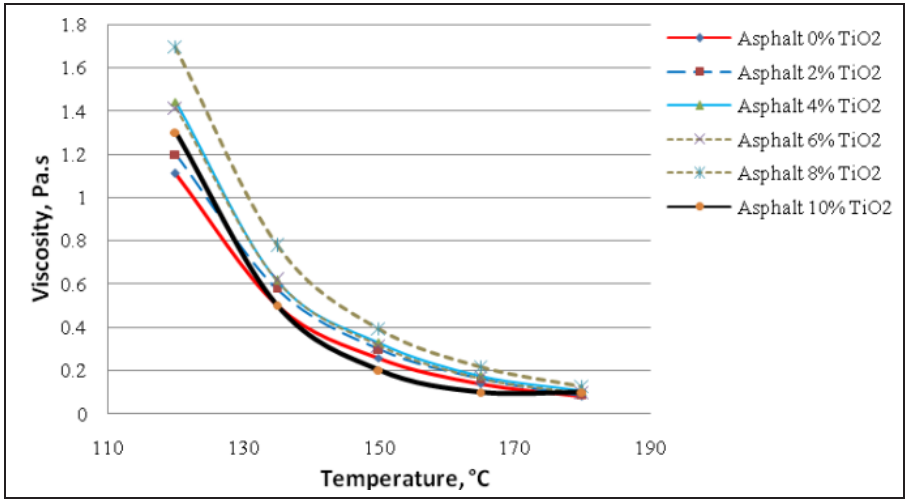

Fig. 2. Rotational viscosity of asphalt $80 / 100$ and $\mathrm{TiO}_{2}$ blends.

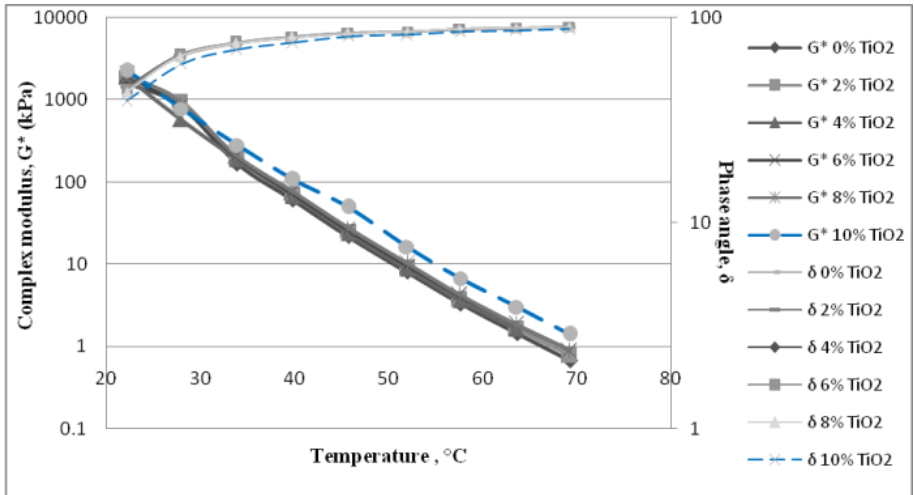

Fig. 3. Isochronal plots of the Complex Modulus $\mathrm{G}^{*}$ at $1 \mathrm{rad}$.

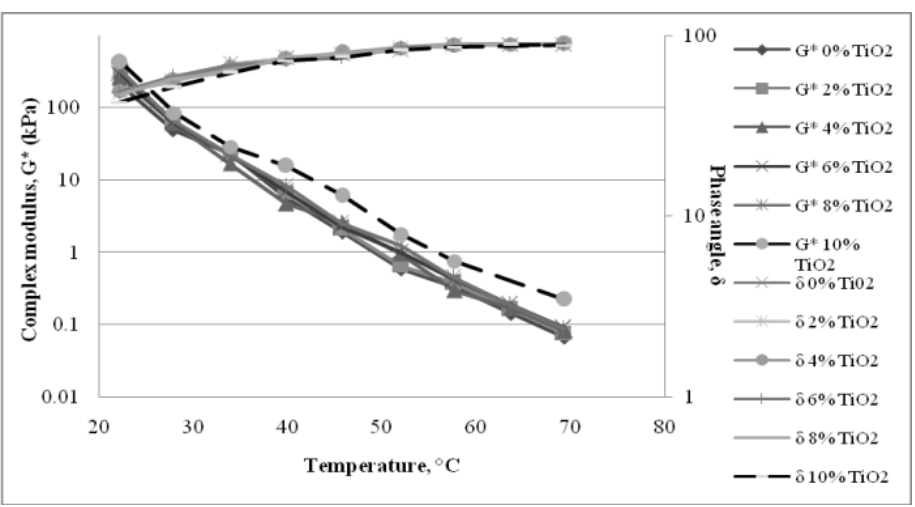

Fig. 4. Isochronal plots of the Complex Modulus $\mathrm{G}^{*}$ at $10 \mathrm{rad}$.

\subsubsection{Rheological master curve}

Master curve are used to representation of rheological measurements, such as the complex modulus or phase angle at varies frequencies and temperature. In the present case, the master curve reflects the time dependency of bitumen over a wide range of loading times. It start with the selection of a reference temperature is selected and then the data at all other temperatures are shifted horizontally with respect to time to produce a single smooth curve. The frequency dependence of $\mathrm{G}^{*}$ for original asphalt and asphalt $10 \% \mathrm{TiO}_{2}$ were assessed 
in Fig. 5 by producing rheological master curves at a reference temperature of $40^{\circ} \mathrm{C}$. The shifting was done by using the shift factor, which varies for each test temperature. Other asphalts with lower percentage of $\mathrm{TiO}_{2}$ are not included due only slightly comparable with the asphalt original. The asphalt $10 \% \mathrm{TiO}_{2}$ are shown to be the most comparable among other percentage. It is noted that increases in the complex modulus upon increasing $\mathrm{TiO}_{2}$ are observed. In general, the complex modulus of the asphalt $10 \% \mathrm{TiO}_{2}$ is increasing at low and high load frequency as the phase angle slightly lower than original asphalt (refer Fig. 3 and Fig. 4) that means it has better elastic recovery performance [8].

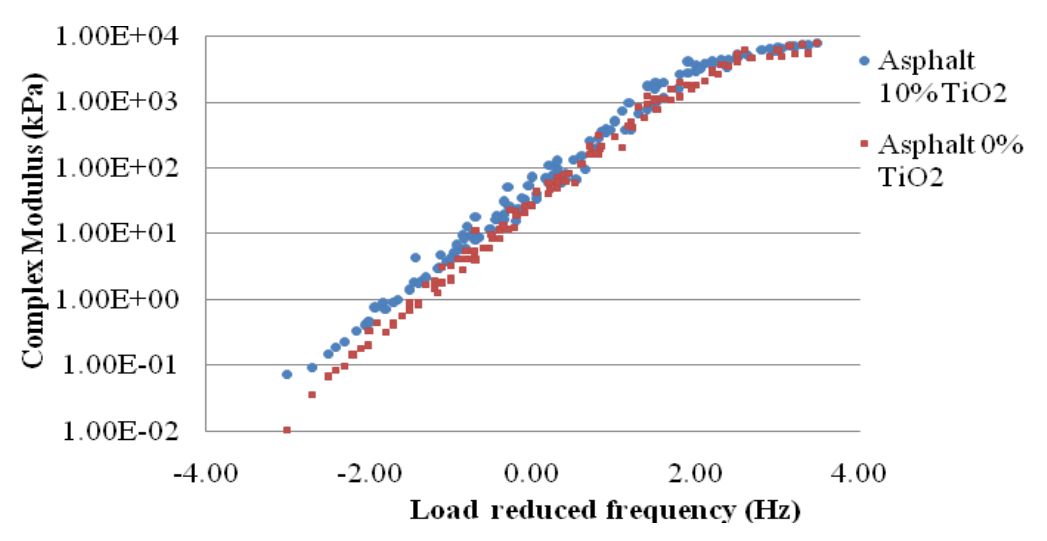

Fig. 5. Complex modulus master curve for original asphalt and asphalt $10 \% \mathrm{TiO}_{2}$ at the reference temperature of $40^{\circ} \mathrm{C}$.

\section{Conclusions}

In this study, the physical and rheological characteristic of the asphalt $\mathrm{TiO}_{2}$ were investigated using conventional and DSR test. The following findings and conclusions can be drawn:

- Base on penetration, softening point, viscosity and ductility test, it was approved that the hardness of asphalt increased, thus resulting improvement in temperature susceptibility.

- The isochronal plot reveals an increasing in stiffness (complex modulus) as a result of the improvement temperature susceptibility for asphalt $10 \% \mathrm{TiO}_{2}$, while other blends are slightly difference from original asphalt.

- The asphalt $10 \% \mathrm{TiO}_{2}$ elastic behaviour (phase angle) was slightly increase compared with the base asphalt.

The authors wish to thank the Universiti Tun Hussein Onn Malaysia. This study was funding by Ministry of Higher Learning Malaysia under FRGS Grant, vot number1458.

\section{References}

1. M.E. Abdullah, K.A. Zamhari, R. Buhari, N. Hidayah, M. Kamaruddin, N. Nayan, R.P. Jaya, Jurnal Teknologi 4, 69-76 (2015)

2. G. Shafabakhsh, S.M. Mirabdolazimi, M. Sadeghnejad, Constr. Build. Mater. 54, 566-571 (2014)

3. J. Yang, S. Tighe, Procedia - Social and Behavioral Sciences 96, 1269-1276, 
(2013)

4. X. Chen, S.S. Mao,. Titanium Dioxide Nanomaterials: Synthesis, Properties, Modifications, and Applications (2007)

5. J.T. Yates, Surface Science 603, (10-12), 1605-1612, (2009)

6. A. Fujishima, T.N. Rao, D.A. Tryk, Titanium dioxide photocatalysis 1, 1-21 (2000)

7. C. Fang, R. Yu, S.Liu, Y. Li, J. Mater. Sci. Technol 29 (7), 589-594, (2013)

8. S.I.A. Ali, A. Ismail, N.I.M. Yusoff, M.R. Karim, R.A. Al-Mansob, D.I. Alhamali, Constr. Build. Mater. 93, 326-334 (2015)

9. R.A. Al-Mansob, A. Ismail, A.N. Alduri, C.H. Azhari, M.R. Karim, N.I.M. Yusoff,. Constr. Build. Mater. 63, 242-248, (2014) 